\title{
Exploration of innovative education model for Jingdezhen ceramic art design
}

\author{
Xiumei Wu
}

School of Management and Economy, Jingdezhen Ceramic University, Jingdezhen, 334000, China

\begin{abstract}
Jingdezhen ceramic art and design education has its own features, and need to be integrated into other art and design disciplines, forming a unique form of education, in recent years, through constant communication pattern formed part of the education innovation, make the design of ceramic art education continuously made new achievements, in both the base characteristics at the same time to the internationalization development. Jingdezhen ceramic education along with the development of Jingdezhen ceramic art, now has a history of one hundred years, constantly in the development of the one hundred reform and adjustment in order to promote the development of ceramic art innovation. Nowadays Jingdezhen ceramics institute has been upgraded to ceramic university, bachelor, master, doctor admissions integration, in order to meet the needs of the development of ceramic industry, ceramic art design education adjustment and innovation unceasingly, on the one hand, break traditional the thought of practice and theory, has been a lot of attention in recent years theory study, from the academic enhance the cultural quality of ceramic art majors, On the other hand, in practice, strengthen the foreign exchange, exchange in the form of diversification, specific strategies use please come in and go out of form, this form of implement enlarged the teacher and the students' knowledge, further to ceramic art design education promotion out, too.
\end{abstract}

Keywords: Ceramic art design; Education; Innovation.

\section{Introduction}

Please come in and compares freedom policy implementation scope widely, mainly divided into three topics: academic, design practice, the classroom teaching.

First, please come in from the perspective of academic exchange, the annual academic exchanges, invite domestic and foreign experts to academic lectures. In recent years, the central China international design BBS, "cultivate forum" held on a regular basis each month, all of these are come on in the art design at home and abroad well-known experts and ceramic art celebrities to teach academic theory.

Chinese art of human association, China art research institute, deputy director of the institute of Chinese culture, doctoral tutor, a visiting professor at the school Fang Lili had done for college teachers and students of the modern value of the "artistic anthropology" academic report; Nanjing college of art Liang Chengping Dr "hand drawing illustration" academic lectures; Famous ceramic archaeological experts, ceramic research institute of Beijing university professor, doctoral supervisor QuanKui mountain as titled "ancient jiangxi jingdezhen porcelain making handicraft prevue" lecture, the China international economic and trade arbitration commission arbitrators, Chinese academy of social sciences, doctoral supervisor li md, deputy director of center for intellectual property rights for school students "some frontier problems of intellectual property law" of academic lectures, and so on.

Second, from the practices of ceramic art design, please come in, invite some ceramics entrepreneur, and design elite celebrities to lecture on business knowledge. Such as in January 2016, no. 4 in the morning, the guangzhou list decoration, deputy general manager $\mathrm{Mr} \mathrm{Yu} \mathrm{Chuanxin,}$ jingdezhen thousands of paper, design director ms yu-juan he design student on the soft outfit for the environment and the difference between hard outfit and relationships. Lectures from practices began to recognize the concept of soft outfit with hard outfit, understanding the fundamental difference, students brought new enlightenment for environment design. After the lecture, students and $\mathrm{Mr} \mathrm{Yu}$ Chuanxin, ms yu-juan he makes a lot of interaction, the scene is very warm and harmonious atmosphere. 
Late on June 27, 2016, Taiwan designers Wang Gutian teacher at the art institute of design on the first floor hall for our product design student held a lecture on the industrial design and industrial demand. Wang Gutian teacher in the lecture to the students talk about their own views: first, the product design company or enterprise need fresh blood (graduate) in the company's new projects, new graduates do not be afraid of their own aspect of knowledge is not enough, companies need your momentum. Second, graduates must make every effort to enter the design scope of relatively large enterprise or the company. Dried up, so that to grow, not thinking as far as possible don't go into those products do only a small company. Third, college students, especially product design students should make good use of holidays, to participate in the actual project or conducting market research, continue to expand their horizons and improve design hunger. Fourth, college students must participate in the actual project, enhance practical ability.

2016 Turing Turing innovation experience (Shanghai) and the university of jingdezhen ceramic art institute of design cooperation conducted for $7 * 24$ (hours) to visit the interaction design work. On the morning of June 23, at the university of Jingdezhen ceramic art design, dean of the school of Mario zhang speech, workshop officially opened. The workshop organised by deputy director of the product design from tsinghua, Turing $\mathrm{Xu}$ Liu zong led by deputy general manager, design director continue Xue Youxi, interaction designers, user research director Qiu Wenping study on interaction design to guide the students. The students take part in the workshop in school undergraduate, graduate students, a total of more than 70 people.

In addition to please the professional of celebrities to give lectures, the school also please government departments to guide the work, please press that can out of Jingdezhen Ceramics University to expand the propaganda, towards internationalization.

Third, from the teaching of ceramic art design implementation, please come in, invite foreign potters to the classroom to students on the course. Please foreign potters to undergraduate students, considering the problem of language communication, equipped with ceramic college teacher in Chinese during class time.

\section{The implementation of going out strategy}

In addition to actively promote please well-known both at home and abroad to teach new knowledge of jingdezhen ceramics institute, institute of ceramics is also actively implement going out strategy. Such as teachers' personal ceramic works exhibitions regularly both at home and abroad, visits to the ceramic enterprises, institutions to domestic learning experience, and so on.

On September 11 and 12, 2015, delegation of Jingdezhen ceramics institute under the guidance of the vice-president professor NingGang Limoges visited France national higher college of art.

In January 2016, Jingdezhen ceramic institute delegation led by party secretary Guo Jiezhong Limoges visited France national higher art college, Pyrenees higher art college, three of the national academy of fine arts college of Bordeaux, and was invited to visit France wave city government.

On November 22 to 24, 2015, our hospital dean professor Mario zhang, vice President of the leading Kang Xiu machine, Guo Yuchuan line of five people to shandong college of art communication research, by shandong college of art design, dean of the school of JingLei, far from macro, vice President of the warm reception, the two sides held a symposium. Conference, JingLei dean in our line of arrival, a warm welcome, and from the teaching of undergraduate course, development scale, professional disciplines, teaching staff, personnel training, laboratory construction, the artistic creation and innovation, etc describes the present situation of college development. Mario zhang dean first on behalf of the college of shandong college of art design college of reception to thank, is contracted to review the development process of the art institute of design and educational history, and points out that in recent years, some problems existing in the teaching, college of shandong college of art design have a lot of experience is worth our using for reference and study and hope that the two sides to further strengthen communication and complement each other, common development. Our line of Shandong College of art laboratory, classroom, studio, 
and consulting some about the operation and management of the workshop. During the visit, the two sides is the laboratory construction, mentors studio set up, such as the double tutorial system of running a school unitedly of the factors for the interaction.

In the enterprise, products demonstration zhi-lin li, chairman of the enthusiasm and meticulous to explain the development of the enterprise culture, this paper introduces the rough stone marble from mining to research and development, and how to applied to ceramic tile products, this paper introduces the features of different types of ceramic tile, about the development of enterprise is a step by step, how to break through the materials, equipment and technology, to develop into today in many marble tile industry occupies an important position in the business elite. After finished, during a visit to exhibit products, Zhang Yuanchang line and direction of the talent training of college graduates and how to improve in the future to strengthen practice and students and market cooperation and li and so on has carried on the communication negotiations.

October 30, 2015 to November 2, Mario zhang dean, Kang Xiu machine, Guo Yuchuan laboratory personnel and the department, associate dean of a line, on the teaching and experiment to arts college of Shanghai construction investigation.

The first is to visit the Shanghai institute of visual art. Shanghai institute of visual art was founded in September 2005, is a state-owned investment is given priority to, at the same time to absorb other social forces, mix all of the new comprehensive arts ordinary undergraduate course colleges and universities. In April 2013, approved by the national ministry of education, from Fudan University, Shanghai institute of visual art to set up an independent set of Shanghai institute of visual art. Art institute of design a line by design institute Ye Ping President, yao-ming Chen, vice President of the warm reception, and a discussion was carried out. At the meeting, President of Ye Ping introduces the Shanghai institute of visual art design school of educational history, mode of running a school and scientific research, especially introduces the master of the school system, teaching reform measures such as the studio system. After the meeting, the dean Ye Ping personally led, visited the school of design in our line teaching fields and ceramic and glass, metal process, woodworking, clothing technology, paint and other laboratory and DE rice master studio.

Followed by a visit to the Shanghai vocational college of arts and crafts, vice President of the hospital professor min warmly received in our line. Min wang, dean of the introduction, Shanghai vocational college of arts and crafts is Shanghai the only independent setting of art design in higher vocational colleges, and the Shanghai only undertake the reform of national education system of higher vocational colleges, is equipped with international designers, arts and crafts master, folk art master studio, gradually formed to production-oriented training workshops and various studios as the main body of running form. Min, vice President of the accompanying our line visited the master studio, classroom, laboratory and other places.

Finally, in the domestic design at the recommendation of the well-known professor Lin Yang, visit the design Institute of Tongji University. Tongji university school of design, from the department of architecture and urban planning in tongji university art design development, in May 2009, Tongji University, draw lessons from the newest idea and mode of design and innovation subjects, on the basis of the art design department of Tongji University, tongji university school of design. By professor Lin Yang, assistant dean liu wei, accompanied by the teacher, our line of a visit to the design institute of tongji university experimental teaching center, including creative workshop, metalworking workshop, carpentry workshop, plastic workshop, jewelry shop, experimental sites such as digital lab and the location of the classroom, classroom and related teaching place and visited the hospital. Dean Professor LouYongQi in symposium introduced something about the school teaching and scientific research and cooperation and our vision, Mario zhang dean said, hope to establish cooperation relationship with the school, strengthen communication, and learn from other universities and introducing the experience of related good. After a visit to the lins' professor Yang master studio, introduces the construction background of the studio and run, and warm hospitality and photographs. 
The administrative leadership to Shanghai investigation design Art College, through research and investigation, insufficient knowledge of our hospital, study construction experience of other universities, deepen our academic and artistic communication, as the design for the construction of the teaching and experiment of the art institute of play the role of promoting.

\section{Summary}

Jingdezhen ceramic art design education innovation model firstly need to come in, from the academic exchanges to invite experts at home and abroad in terms of academic lectures. Please come in from the practice of ceramic art design, invite some ceramics entrepreneur, and design elite celebrities to lecture on business knowledge. College students, especially product design students should make good use of holidays, to participate in the actual project or conducting market research, continue to expand their horizons and improve design hunger. At the same time also must participate in the actual project, and constantly improve the actual beginning ability. Second, to take the initiative to go out strategy, regular visit to the field in the ceramic enterprise at home and abroad, domestic institutions to learn more experience, so as to better for ceramic design education modernization, internationalization.

In this paper, for the Jingdezhen ceramics university center for collaborative project: "jingdezhen ceramic art education from the evolution of modern to contemporary".

\section{References}

[1] Xiu-mei wu: the inheritance and change - jingdezhen porcelain development research of the republic of China, Beijing, Guangming daily press, 2012, 5.

[2] Xiu-mei wu: the traditional handicraft culture research - ceramic hangzhou fan, for example, Beijing: Guangming daily press, 2013, 5.

[3] YanYi: "Jiang Xitao industry administration briefly" / / materials of jingdezhen history (2), the Chinese people's political consultative conference literature and history research committee, also the commission yaumcha county offset presses, 1992.

[4] Zhang Zhaojun, Sun Yanjing: "the modern Chinese cultural history," Beijing: zhong hua press, 2012.

[5] Yong-feng Yang: "jingdezhen ceramic ancient and modern talking", Beijing: Chinese literature publishing house, 1991.

[6] Jihong ye: the traditional arts and cultural regeneration effect on Suzhou town lake, Beijing: QunYan publishing house, 2005. 